\title{
Predictors of oral bisphosphonate prescriptions in post-menopausal women with osteoporosis in a real-world setting in the USA
}

\author{
C. Asche • R. Nelson • C. McAdam-Marx • M. Jhaveri • \\ X. Ye
}

Received: 26 May 2009 / Accepted: 26 August 2009/Published online: 2 October 2009

(C) International Osteoporosis Foundation and National Osteoporosis Foundation 2009

\begin{abstract}
Summary We identified factors associated with oral bisphosphonate treatment in 50+-year-old female patients with a first fracture, osteoporosis diagnosis, or BMD $\leq-2.5$ in the Geisinger Health System electronic health record database. Treatment was positively associated with age, oral corticosteroids, and smoking, and negatively associated with body mass index and bone mineral density scores.

Introduction To identify factors associated with oral bisphosphonate treatment in patients with an indicator for post-menopausal osteoporosis.

Methods Females age 50+ years with a first fracture, osteoporosis diagnosis, or bone mineral density (BMD) $\leq-2.5$ (index date) were identified in the Geisinger Health System electronic health record database. Treatment was defined as an oral bisphosphonate prescription order (risedronate sodium, ibandronate sodium, or alendronate) $\leq 90$ days post-index date. Treatment rates were assessed and a multivariate logistic model was used to identify
\end{abstract}

C. Asche $(\bowtie) \cdot$ C. McAdam-Marx $\cdot$ X. Ye

University of Utah College of Pharmacy,

Salt Lake, UT, USA

e-mail: carl.asche@pharm.utah.edu

C. Asche

University of Utah Center on Aging,

Salt Lake, UT, USA

R. Nelson

University of Utah School of Medicine,

Salt Lake, UT, USA

e-mail: richard.nelson@utah.edu

M. Jhaveri

Sanofi-Aventis,

Bridgewater, NJ, USA predictors of treatment separately for patients with fracture (FRAC) and with diagnosis or low BMD (ICD-9-BMD). Results The FRAC group had 2,003 female patients with a mean (SD) age of $69.0( \pm 11.3)$ years and the ICD-9-BMD group had 12,976 female patients with a mean (SD) age of $66.9( \pm 10.0)$ years. Within 90 days of the index date of fracture, diagnosis, or low BMD score, 188 (9.4\%) patients in the FRAC group and 5,395 (41.6\%) in the ICD-9-BMD group received treatment. Treatment was positively associated with age and oral corticosteroids and negatively associated with body mass index and subsequent BMD in both groups. Smoking currently was positively associated with treatment in the ICD-9-BMD group.

Conclusion Certain patient characteristics are predictors of physicians prescribing oral bisphosphonates. However, many patients remain untreated.

Keywords Bone mineral density · Fracture - Oral bisphosphonate $\cdot$ Osteoporosis $\cdot$ Real world data

\section{Introduction}

Osteoporosis is a skeletal disorder characterized by low bone mineral density (BMD) and a disruption of normal bone architecture. It is a major risk factor for fracture, which leads to substantial morbidity and mortality [1]. Osteoporotic fractures are common; it is estimated that one half of all postmenopausal women will have a fracture in her lifetime [2]. Hip fractures reduce life expectancy, by $25 \%$ in one study [3], and are associated with a substantial decrease in quality of life [4]. The estimated societal cost of osteoporotic fractures in the USA was $\$ 13.8$ billion in 1995 [5]. Osteoporosis will likely become increasingly burdensome as the proportion of the US population that is elderly increases. 
The aim of treatment of established osteoporosis is to maintain and, ideally, to restore bone strength with the ultimate goal of preventing fractures. There are currently a number of FDA-approved agents for the treatment of osteoporosis including bisphosphonates (e.g., alendronate, ibandronate, or risedronate), raloxifene, teriparatide, and calcitonin. Estrogen replacement therapy is indicated for the prevention of osteoporosis. All of these agents have been shown to increase BMD and several have shown efficacy in fracture risk reduction [6].

Thus, drug therapy is a key therapeutic component in preventing osteoporosis fractures in patients at risk for fracture. However, it is estimated that only $36 \%$ of women with post-menopausal osteoporosis are treated with any agent for the prevention or treatment of osteoporosis, and specifically, only $16 \%$ were treated with bisphosphonate or calcitonin [7]. A number of studies have examined predictors of treatment to help understand what factors clinicians are weighting most heavily in determining whether to treat osteoporotic patients. Ideally, predictors of treatment should mirror predictors of fracture. Surprisingly, many of these studies have found that this is not necessarily the case. Increased age, oral corticosteroid usage, and smoking status are all risk factors for osteoporosis and fracture [8] but have often been found to have either a negative association or no association with treatment administration [9-20]. Yet several studies have found that either older patients are less likely to get treatment $[12,18,22]$ or there is no association between age and treatment [20, 23].Low T-scores on BMD tests are strong predictors of fracture but are often not available for researchers. In this study, we distinguish osteoporotic patients based on having a fracture or having a low BMD T-score or a diagnosis code for osteoporosis. Few studies have examined factors associated with treatment in patients with these specific characteristics [11, 21]. As noted, the risk of fracture increases with age.

The objective of this study was to identify predictors of osteoporosis treatment. This was done separately for two subgroups of osteoporosis patients: (1) those with a fracture (FRAC group) (2) and those with either an International Classification of Diseases (ICD)-9 code for osteoporosis and/or a low $(\leq-2.5) \mathrm{T}$-score from a BMD test (ICD-9-BMD group). Potential predictors were included based on their association with bone health and fall risk. The evaluated predictors included weight, body mass index (BMI), smoking status, excessive alcohol consumption, a history of previous fractures, BMD T-score, comorbid conditions, and drug exposures. In this study, we focused specifically on prescribing for oral bisphosphonates (risedronate, alendronate, and ibandronate). Bisphosphonates are a commonly used class of prescription drugs for the treatment of osteoporosis [24], and in patients with low bone density, bisphosphonate have been shown to reduce fracture risk by $40-50 \%$ [25].

\section{Methods}

Study design

This study utilized a retrospective cohort design to evaluate the association between observable clinical characteristics and drug treatment for osteoporosis.

\section{Data}

We used data from the Geisinger Health System (GHS) from January 1, 2000-June 30, 2007. GHS was founded in 1915 and is a physician-led organization comprised of 650 plus physicians, 75 medical and surgical specialties, and 42 pediatric medical and surgical subspecialties. GHS, which also has one of the largest not for profit rural HMOs in the USA, has three existing hospitals (primary to quaternary care) and 41 community practice offices. The GHS service area is limited to the state Pennsylvania. The core of the data originates from an electronic medical record (EMR) infrastructure that contains longitudinal clinical patient data including lab results for nearly three million patients from 1996 to 2006. A unique feature of this dataset is the availability of diagnostic testing results. For the present study, we utilized results from BMD tests. The data was obtained through MedMining (a Geisinger Health System Business), which has developed a proprietary, Health Information Portability and Accountability Act compliant research database based on the GHS data.

\section{Study population}

The cohort population was selected based on specific criteria. Female patients age 50 and older were selected for inclusion into the study if they had at least one of three separate identifiers for osteoporosis from January 1, 2000 through June 30, 2007: (1) ICD-9 codes for osteoporosis (733.0, 733.00, 733.01, 733.03, 733.09); (2) a BMD T-score of -2.5 or less; or (3) a fracture on or after age 50 with no fracture in the 6 months prior. Locations for fractures were identified by ICD-9 codes (Table 1) for the clavicle, hip, humerus, pelvis, leg, wrist, and spine. The date of osteoporosis identification was designated as the patient's index date. Patients were excluded if they were not continuously active in the database for $365+$ days prior to and $365+$ days after the 
Table 1 Fragility fracture (Inclusion and Outcome Criteria)

\begin{tabular}{|c|c|c|}
\hline Fracture site & ICD-9-CM & \\
\hline 1. Clavicle (closed) & Closed & $810.0 \mathrm{x}$ \\
\hline \multirow[t]{4}{*}{ 2. Hip (closed) } & Pathologic & 733.14 \\
\hline & Transcervical & $820.0 x$ \\
\hline & Pertrochanteric & $820.2 x$ \\
\hline & Unspecified & $820.8 x$ \\
\hline \multirow[t]{4}{*}{ 3. Humerus (closed) } & Pathologic & 733.11 \\
\hline & Upper end & $812.0 \mathrm{x}$ \\
\hline & Shaft/unspecified & $812.2 x$ \\
\hline & Lower end & $812.4 x$ \\
\hline \multirow[t]{4}{*}{ 4. Pelvis (closed) } & Acetabulum & $808.0 x$ \\
\hline & Pubis & $808.2 \mathrm{x}$ \\
\hline & Other specified & $808.4 x$ \\
\hline & Unspecified & $808.8 x$ \\
\hline \multicolumn{3}{|l|}{ 5. Leg } \\
\hline \multirow[t]{3}{*}{ Femur (closed) } & Pathologic & 733.15 \\
\hline & Shaft/unspecified & $821.0 x$ \\
\hline & Lower end & $821.2 x$ \\
\hline \multirow[t]{4}{*}{ Tibia/Fibula (closed) } & Pathologic & 733.16 \\
\hline & Upper end & $823.0 x$ \\
\hline & Shaft & $823.2 \mathrm{x}$ \\
\hline & Unspecified & $823.8 \mathrm{x}$ \\
\hline \multirow[t]{5}{*}{ 6. Wrist (closed) } & Pathologic & 733.12 \\
\hline & Forearm upper end & $813.0 x$ \\
\hline & Shaft & $813.2 x$ \\
\hline & Lower end & $813.4 x$ \\
\hline & Unspecified & $813.8 x$ \\
\hline \multirow[t]{5}{*}{ 7. Spine/vertebral (closed) } & Pathologic & 733.13 \\
\hline & Cervical, closed & $805.0 x$ \\
\hline & Dorsal, closed & $805.2 x$ \\
\hline & Lumbar, closed & $805.4 x$ \\
\hline & Unspecified, closed & $805.8 \mathrm{x}$ \\
\hline
\end{tabular}

index date, if they had both a fracture and at least one of the other two osteoporosis identifiers, or if they had a diagnosis for a condition known to impact bone density and quality (i.e., Paget's disease (ICD-9: 731.xx), secondary malignant neoplasm of bone and bone marrow (ICD-9: 198.5), and osteomylitis (ICD-9: 730.xx)).

\section{Statistical analysis}

Patients were stratified into two groups, FRAC and ICD-9$\mathrm{BMD}$, based on reason for inclusion. Descriptive statistics, including proportion of patients treated, were used to characterize the baseline demographic and clinical characteristics of patients in both groups.

A logistic regression was used to identify predictors of osteoporosis treatment with an oral bisphosphonate (risedr- onate, alendronate, or ibandronate). Patients were identified as treated if they had a prescription for one of the three drugs on the index date or up to 90 days post-index date. Regressions were run separately for each of the two patient groups. Independent variables included age at index date (50-64, 65-74, and 75+), BMI $\left(\leq 24 \mathrm{~kg} / \mathrm{m}^{2}, 25-29 \mathrm{~kg} / \mathrm{m}^{2}\right.$, $30-34 \mathrm{~kg} / \mathrm{m}^{2}$, and $35+\mathrm{kg} / \mathrm{m}^{2}$ ), smoking status, excessive alcohol consumption, fall history, insurance status (Medicare, private insurance, or no insurance), presence of an order for a BMD test, and BMD T-score. The value for the BMD T-score variable was the test result for the hip, if available. If the hip T-score was not available, a spine test result was used, and if neither a hip or spine result was available, a forearm score was used. Values for the BMD T-score variable included test results within the first 90 days after the index date and was dichotomized based on whether the value was greater than or less than or equal to -2.5 . Therefore, patients in the FRAC group, who by definition did not have a T-score $\leq-2.5$ on the index date, may still have a value for this variable below this threshold if it was measured in the first 90 days post-index. Furthermore, while it was not possible to link the cause of the fracture for patients in the FRAC group to a specific fall, if the fracture was the result of a fall, that fall would be captured by the fall history variable. Also included were diagnoses of comorbidities associated with bone health such as aortic atherosclerosis, diabetes, thyroid disease, and malnutrition. Indicators for the use of drugs over the study period whose exposures are associated with fracture risk were also included (e.g., chemotherapy, oral corticosteroids, thyroid replacement therapy, and furosemide therapy). Finally, a Charlson Comorbidity Index (CCI) score was calculated for each patient based on comorbidities documented on or one year prior to their index date [26].

Initially, a forward selection process was undertaken by running univariate regressions with each independent variable. Variables whose coefficients had $p$ values of $\leq 0.10$ were chosen to be included in the full multivariate regression. As a sensitivity analysis, calculations for proportion of treated patients as well as regression models were repeated using post-index date windows for defining treatment of 180 and 365 days.

All statistical tests were performed at a 0.05 significance level using Stata SE v. 9 (StataCorp, College Station, Texas) and SAS v. 9 (Cary, NC.)

\section{Results}

Figure 1 is a Venn diagram depicting the portion of patients with each of the three osteoporosis identifiers. The FRAC group consisted of 2,003 females and the ICD-9-BMD group was made up of 12,976 females. A total of 260 


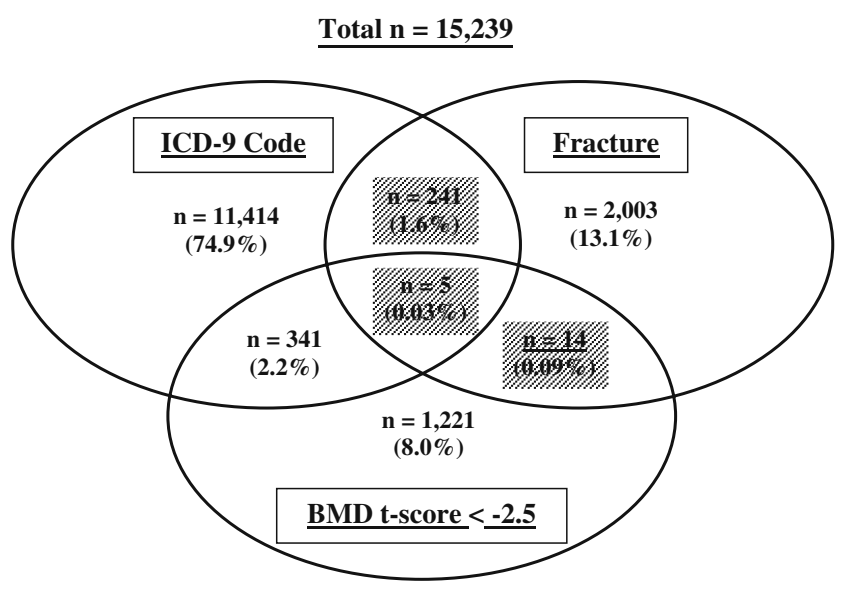

Note: Bone Mineral Density (BMD); International Classification of Diseases - 9 (ICD-9) Shaded patient counts were excluded from the final analysis.

Fig. 1 Venn diagram showing portion of patients with each osteoporosis identifier. Bone Mineral Density (BMD); International Classification of Diseases 9 (ICD-9) Shaded patient counts were excluded from the final analysis

patients, depicted in shaded regions in the figure, had both a fracture and either a low BMD T-score or an ICD-9 code for osteoporosis. These patients are included in Fig. 1 for illustrative purposes but were excluded from the analysis in order to isolate the two patient groups.

The mean age was $69.0(\mathrm{SD} \pm 11.3)$ in the FRAC group and $66.9(\mathrm{SD} \pm 10.0)$ in the ICD-9-BMD group (Table 2). A higher proportion of patients in the ICD-9-BMD group had a BMD ordered at any point in the study period compared to patients in the FRAC group (62.5\% vs. $16.9 \%)$ and had lower average $\mathrm{T}$-scores for each of the three sites (hip, -1 $[\mathrm{SD} \pm 1.1]$ vs. $-0.7[\mathrm{SD} \pm 1.2] ;$ spine, $-1.3 \quad[\mathrm{SD} \pm 1.0]$ vs. $-0.8[\mathrm{SD} \pm 1.5]$; forearm, $-1.5[\mathrm{SD} \pm 1]$ vs. -1.2 $[\mathrm{SD} \pm 1.1])$. In both patient groups, most patients either had never smoked (ICD-9-BMD, 60.3\%; FRAC, 58.9\%) or were former smokers (ICD-9-BMD, 25.1\%; FRAC, $58.9 \%$ ). Most of the patients in the FRAC group had a CCI $\geq 3$ (63\%), $16.3 \%$ were taking an oral corticosteroid, and $2.5 \%$ had a diagnosis for rheumatoid arthritis. In the ICD-9-BMD group, $46 \%$ of the patients had a CCI $\geq 3$, $14.4 \%$ were taking an oral corticosteroid, and $4.4 \%$ had a diagnosis of rheumatoid arthritis.

Only $188(9.4 \%)$ of the patients in the FRAC group were prescribed treatment in the first 90 days post-index date, while 5,395 $(41.6 \%)$ patients in the ICD-9-BMD group were treated during this same time period (Table 3). Treatment was prescribed for $13.4 \%$ and $18.5 \%$ of FRAC patients in the 180 days and 365 days following the index date, respectively. For the ICD-9-BMD patients, $45.9 \%$ had been prescribed treatment within 180 days while $49.3 \%$ had been prescribed treatment within 365 days.

In Table 4, results from the logistic regressions are presented for patients in the FRAC group. Baseline results for which treatment was defined as a prescription in the first 90 days following fracture are presented along with alternative treatment definitions of 180 and 365 days. Individuals between the ages of 65 and 74 were significantly more likely to get treatment $(\mathrm{OR}=1.77, p=0.009)$ compared with patients between 50 and 64. A low BMD T-score $(\leq-2.5)$ after fracture date was significantly associated with increased likelihood of receiving treatment $(\mathrm{OR}=4.90, p<0.001)$. Obese patients were less likely to receive treatment than underweight or normal weight patients $(\mathrm{OR}=0.53, p=0.03)$, and those taking an oral corticosteroid were more likely to receive treatment $(\mathrm{OR}=1.67, p=0.01)$. The effects of covariates on the likelihood of bisphosphonate treatment were similar using treatment windows of 180 and 365 days post-index date; however, more odds ratios reached statistical significance as the number of treated patients increased.

Results from logistic regressions for patients in the ICD-9-BMD are presented in Table 5. Treatment receipt was positively associated with age, with patients between the ages of 65 and $74(\mathrm{OR}=1.18, p<0.001)$ and 75 and older $(\mathrm{OR}=1.57, p<0.001)$ significantly more likely to receive treatment compared with patients between 50 and 64. A low BMD T-score $(\leq-2.5)$ was significantly associated with an increased likelihood of receiving treatment $(\mathrm{OR}=1.32, p=0.002)$. Patients who used to smoke $(\mathrm{OR}=0.76, p<0.001)$ or who never smoked $(\mathrm{OR}=0.72, p<0.001)$ were significantly less likely to receive treatment than those who currently smoke. BMI was negatively associated with treatment. Overweight $(\mathrm{OR}=0.81, p<0.001)$, obese $(\mathrm{OR}=0.54, p<0.001)$, and very obese $(\mathrm{OR}=0.46, p<0.001)$ patients were less likely to receive treatment than those who were underweight or normal weight. Patients with higher CCI $(\mathrm{OR}=0.96$, $p<0.001)$ were less likely to receive treatment, while those taking an oral corticosteroid $(\mathrm{OR}=1.34, p<0.001)$ and those with rheumatoid arthritis $(\mathrm{OR}=1.40, p<0.001)$ were more likely to receive treatment. Results were similar using treatment windows of 180 and 365 days.

\section{Discussion}

The purpose of this study was to quantify how fracture risk factors are associated with physicians prescribing bisphosphonate treatment in women with postmenopausal osteoporosis. The treatment rate was low, especially in the FRAC group, with merely $9.4 \%$ having a prescription order for an oral bisphosphonate in the first 90 days following a fracture and only $18.5 \%$ having such a prescription order if the follow-up period is extended to 1 year. This result is similar to those found in other studies where treatment rates have 
Table 2 Baseline characteristics

\begin{tabular}{|c|c|c|c|c|}
\hline & \multicolumn{2}{|c|}{ Fracture $(n=2003)$} & \multicolumn{2}{|c|}{ Low BMD or ICD-9 $(n=12,976)$} \\
\hline & $n /$ mean & $\%$ or $\mathrm{SD}$ & $n /$ mean & $\%$ or $\mathrm{SD}$ \\
\hline Mean age (SD) & 69.0 & 11.3 & 66.9 & 10.0 \\
\hline $50-64$ & 774 & 38.6 & 5,582 & 43.0 \\
\hline $65-74$ & 519 & 25.9 & 4,156 & 32.0 \\
\hline $75+$ & 710 & 35.4 & 3,238 & 25.0 \\
\hline \multicolumn{5}{|l|}{ Race $(n, \%)$} \\
\hline White & 1,980 & 98.9 & 12,819 & 98.8 \\
\hline Black & 6 & 0.3 & 38 & 0.3 \\
\hline Hispanic & 5 & 0.2 & 32 & 0.2 \\
\hline Other & 9 & 0.4 & 75 & 0.6 \\
\hline Unknown & 3 & 0.1 & 12 & 0.1 \\
\hline \multicolumn{5}{|l|}{ Mean baseline BMD T-score (SD) } \\
\hline Forearm & -1.2 & 1.1 & -1.5 & 1.0 \\
\hline Hip & -0.7 & 1.2 & -1 & 1.1 \\
\hline Spine & -0.8 & 1.5 & -1.3 & 1.4 \\
\hline BMD T-score orders $(n, \%)$ & 339 & 16.9 & 8,114 & 62.5 \\
\hline \multicolumn{5}{|l|}{ BMD T-score $(n, \%)$} \\
\hline$\leq-2.5$ & 26 & 1.3 & 560 & 4.3 \\
\hline$>-2.5$ to $\leq-1.0$ & 115 & 5.7 & 3,581 & 27.6 \\
\hline$\geq-1.0$ to $\leq 1.0$ & 156 & 7.8 & 3,283 & 25.3 \\
\hline$\geq 1.0$ & 25 & 1.2 & 310 & 2.4 \\
\hline Missing & 17 & 0.8 & 380 & 2.9 \\
\hline Unknown & 1,664 & 83.1 & 4,862 & 37.5 \\
\hline \multicolumn{5}{|l|}{ Smoking } \\
\hline Current smoker & 185 & 9.2 & 1,285 & 9.9 \\
\hline Former smoker & 486 & 24.3 & 3,262 & 25.1 \\
\hline Never smoker & 1,179 & 58.9 & 7,828 & 60.3 \\
\hline Missing & 153 & 7.6 & 601 & 4.6 \\
\hline \multicolumn{5}{|l|}{ Baseline BMI } \\
\hline Under/normal weight & 232 & 11.6 & 3,051 & 23.5 \\
\hline Over weight & 363 & 18.1 & 3,312 & 25.5 \\
\hline Obese & 402 & 20.1 & 2,790 & 21.5 \\
\hline Very obese & 134 & 6.7 & 500 & 3.9 \\
\hline Missing & 872 & 43.5 & 3,323 & 25.6 \\
\hline \multicolumn{5}{|l|}{ Insurance status $(n, \%)$} \\
\hline Medicaid & 835 & 41.7 & 4,931 & 38.0 \\
\hline Medicare & 709 & 35.4 & 4,710 & 36.3 \\
\hline Commercial & 419 & 20.9 & 3,190 & 24.6 \\
\hline Self-pay & 40 & 2.0 & 145 & 1.1 \\
\hline Excessive alcohol consumption $(n, \%)$ & 8 & 0.4 & 32 & 0.2 \\
\hline Mean Charlson Comorbidity Index (SD) & 2.3 & 1.1 & 2.0 & 1.1 \\
\hline 0 & 217 & 10.8 & 2,015 & 15.5 \\
\hline 1 & 263 & 13.1 & 2,545 & 19.6 \\
\hline 2 & 254 & 12.7 & 2,356 & 18.2 \\
\hline $3+$ & 1,269 & 63.4 & 6,060 & 46.7 \\
\hline Oral corticosteroid $(n, \%)$ & 327 & 16.3 & 1,870 & 14.4 \\
\hline Rheumatoid arthritis $(n, \%)$ & 50 & 2.5 & 575 & 4.4 \\
\hline Fall history $(n, \%)$ & 812 & 40.5 & 1,445 & 11.1 \\
\hline
\end{tabular}


Table 2 (continued)

\begin{tabular}{|c|c|c|c|c|}
\hline & \multicolumn{2}{|c|}{ Fracture $(n=2003)$} & \multicolumn{2}{|c|}{ Low BMD or ICD-9 $(n=12,976)$} \\
\hline & $n /$ mean & $\%$ or $\mathrm{SD}$ & $n /$ mean & $\%$ or $\mathrm{SD}$ \\
\hline Aortic atherosclerosis $(n, \%)$ & 41 & 2.0 & 151 & 1.2 \\
\hline Chemotherapy $(n, \%)$ & 669 & 33.4 & 4,400 & 33.9 \\
\hline Diabetes $(n, \%)$ & 657 & 32.8 & 2,844 & 21.9 \\
\hline Thyroid replacement therapy $(n, \%)$ & 524 & 26.2 & 3,329 & 25.7 \\
\hline Thyroid disease $(n, \%)$ & 842 & 42.0 & 5,201 & 40.1 \\
\hline Furosemide therapy $(n, \%)$ & 695 & 34.7 & 2,693 & 20.8 \\
\hline Malnutrition $(n, \%)$ & 291 & 14.5 & 1,393 & 10.7 \\
\hline
\end{tabular}

$S D$ standard deviation, $B M D$ bone mineral density, ICD-9 International Classification of Diseases $9, B M I$ body mass index

ranged from $16 \%$ to $26 \%$ in patients with fractures during 1 year follow-up periods [7, 27-30]. The rate of treatment within 90 days of diagnosis in the ICD-9-BMD group was also low (41.6\%), and remained low at 1 year after diagnosis of osteoporosis (49.3\%). These treatment rates all fall short of the estimates based on National Osteoporosis Foundation (NOF) guidelines [31]. Based on these guidelines, an estimated $72 \%$ of white women ages 65 and above should receive pharmacologic treatment for osteoporosis. Our findings are more consistent with the World Health Organization fracture risk assessment tool (FRAX ${ }^{\mathrm{TM}}$ ) guidelines which suggest that $23-46 \%$ of postmenopausal women should be treated for osteoporosis [32].

These results illustrate a potential gap in terms of clinical perception of fracture risk in a patient or benefits of therapy and treatment guidelines based on known fracture risk factors. Clinical guidelines recommend treatment in postmenopausal women with a BMD T-score of $\leq-2.5$ or a prior fragility fracture. Other post-menopausal women, who are candidates for treatment, are those with high fracture risk based on a high probability of a fracture within 10 years [31]. The FRAX ${ }^{\mathrm{TM}}$ model was developed to provide a measure of fracture risk based on known fracture risk factors with or without BMD scores [33]. These tools help clinicians quantify risk and therefore help to target patients for treatment. BMD tests are critical in making treatment decisions. Treatment recommendations from the National
Center on Clinical Excellence recommend the use of alendronate in patients with a fragility fracture only if they have a T-score $\leq-2.5$ [34-36].

Thus, fracture risk factors should be drivers of treatment and, therefore, should also be treatment predictors, which was largely observed in this current study. Comparison of these results to those of fracture from other studies reveals some similarities but also many gaps. Low BMD T-scores, smoking, and weight are all significant predictors of fragility fracture which are shown here to be strongly associated with treatment. However, fall history, excessive alcohol consumption, comorbid conditions such as diabetes, thyroid disease, aortic atherosclerosis, and malnutrition, and drug exposures such as chemotherapy and thyroid replacement therapy have all been shown to be associated with fractures, but were not significant predictors of initiation of treatment in this study.

Several of our findings are substantially different from those found in earlier studies though consistent with what we would expect. Earlier studies have reported either no association between age and osteoporosis treatment or that treatment is negatively associated with age [12, 18, 20, 22, 23]. That age is positively associated with treatment in our study, while different from previous studies, makes clinical sense given the strong association of age and osteoporosis and fracture risk [15, 17]. Many other studies have also failed to find as association between oral steroid use and osteoporosis treatment [23, 37-39]. Again, our findings
Table 3 Frequency of patients treated at 90, 180, and 365 days after index date

BMD bone mineral density, ICD-9 International Classification of Diseases

\begin{tabular}{|c|c|c|c|c|}
\hline \multirow[t]{2}{*}{ Number of days from index date } & \multicolumn{2}{|c|}{ Fracture $(n=2,003)$} & \multicolumn{2}{|c|}{ Low BMD or ICD-9 $(n=12,976)$} \\
\hline & $n$ & $\%$ & $n$ & $\%$ \\
\hline 90 days & 188 & 9.4 & 5,395 & 41.6 \\
\hline 180 days & 268 & 13.4 & 5,954 & 45.9 \\
\hline 365 days & 371 & 18.5 & 6,395 & 49.3 \\
\hline
\end{tabular}


Table 4 Logistic regression for osteoporosis treatment-patients with fracture
$B M I$ body mass index, $B M D$ bone mineral density

\begin{tabular}{|c|c|c|c|c|c|c|}
\hline & \multicolumn{6}{|c|}{ Number of days from index date for treatment definition } \\
\hline & \multicolumn{2}{|l|}{90 days } & \multicolumn{2}{|l|}{180 days } & \multicolumn{2}{|l|}{365 days } \\
\hline & Odds ratio & $P$ value & Odds ratio & $P$ value & Odds ratio & $P$ value \\
\hline \multicolumn{7}{|l|}{ Age } \\
\hline \multicolumn{7}{|l|}{$50-64$ (ref) } \\
\hline $65-74$ & 1.764 & 0.009 & 1.784 & 0.002 & 1.780 & $<0.001$ \\
\hline $75+$ & 1.469 & 0.119 & 1.632 & 0.018 & 1.463 & 0.032 \\
\hline \multicolumn{7}{|l|}{ Race } \\
\hline \multicolumn{7}{|l|}{ White (ref) } \\
\hline Other & 0.788 & 0.762 & 0.514 & 0.389 & 0.591 & 0.415 \\
\hline \multicolumn{7}{|l|}{ BMD T-score category } \\
\hline$\leq-2.5$ & 4.900 & $<0.001$ & 3.441 & 0.007 & 5.750 & $<0.001$ \\
\hline \multicolumn{7}{|l|}{$>-2.5$ (ref) } \\
\hline Unknown & 0.128 & $<0.001$ & 0.180 & $<0.001$ & 0.295 & $<0.001$ \\
\hline \multicolumn{7}{|l|}{ Smoking } \\
\hline \multicolumn{7}{|l|}{ Current smoker (ref) } \\
\hline Former smoker & 0.798 & 0.474 & 0.882 & 0.644 & 1.031 & 0.898 \\
\hline Never smoker & 0.930 & 0.799 & 0.954 & 0.852 & 1.059 & 0.795 \\
\hline Unknown & 0.225 & 0.011 & 0.286 & 0.007 & 0.383 & 0.010 \\
\hline \multicolumn{7}{|l|}{ Baseline BMI } \\
\hline \multicolumn{7}{|l|}{ Under/normal weight (ref) } \\
\hline Over weight & 0.804 & 0.428 & 0.774 & 0.274 & 0.802 & 0.274 \\
\hline Obese & 0.532 & 0.031 & 0.584 & 0.027 & 0.462 & $<0.001$ \\
\hline Very obese & 0.545 & 0.146 & 0.465 & 0.035 & 0.301 & $<0.001$ \\
\hline Missing & 0.845 & 0.521 & 0.671 & 0.067 & 0.535 & $<0.001$ \\
\hline Charlson Comorbidity Index & 1.034 & 0.269 & 1.040 & 0.122 & 1.033 & 0.138 \\
\hline Oral corticosteroid & 1.669 & 0.014 & 1.358 & 0.092 & 1.270 & 0.136 \\
\hline Rheumatoid arthritis & 1.650 & 0.254 & 2.179 & 0.031 & 1.765 & 0.092 \\
\hline
\end{tabular}

regarding oral corticosteroid use are consistent with physicians making prescription decisions based on known risk factors. At least one other study found that women with rheumatoid arthritis were less likely to receive treatment [12]. Once more, in finding that patients with this disease are more likely to receive treatment, our results are more consistent with expectations. Finally, while smoking status has not been a significant predictor of treatment in other studies $[9,12]$, it is in ours.

We found that BMI was negatively associated with treatment, while other studies have either found the same result [23] or no significant association between BMI and treatment $[9,11]$. Our findings on BMD T-scores are consistent with several other studies [9-11, 13, 14, 16, 19]. However, previous studies looking at the association between BMD T-scores and treatment have used prospective data sources. This is the first study to find this result using a retrospective database.

Our results, particularly the low prescribing rates, suggest there is room for improvement in prescription drug prescribing for patients with osteoporosis. Efforts to raise clinician's awareness and adoption of the treatment guidelines put forth by the NOF could potentially help reduce fracture rates in women with post-menopausal osteoporosis.

\section{Limitations}

This study provides insight into predictors of postmenopausal osteoporosis treatment in a real-world setting by whether women had a prior fracture or a diagnosis or a low BMD T-score as indicators of osteoporosis. However, several limitations warrant mention. First, the EMR data represents care delivered to study patients within GHS; care delivered by non-GHS providers would likely not be included in the data unless reported by the patient and documented in the EMR, including prescription orders. As a health system, data is more likely to be comprehensive than an EMR that was located in a single site of care, such as an office based EMR system. The 
Table 5 Logistic regression for osteoporosis treatment - patients with low BMD or ICD-9 code
BMI body mass index, $B M D$ bone mineral density, ICD-9 International Classification of Diseases 9

\begin{tabular}{|c|c|c|c|c|c|c|}
\hline & \multicolumn{6}{|c|}{ Number of days from index date for treatment definition } \\
\hline & \multicolumn{2}{|l|}{90 days } & \multicolumn{2}{|l|}{180 days } & \multicolumn{2}{|l|}{365 days } \\
\hline & Odds ratio & $P$ value & Odds ratio & $P$ value & Odds ratio & $P$ value \\
\hline \multicolumn{7}{|l|}{ Age } \\
\hline \multicolumn{7}{|l|}{$50-64$ (ref) } \\
\hline $65-74$ & 1.176 & $<0.001$ & 1.197 & $<0.001$ & 1.248 & $<0.001$ \\
\hline $75+$ & 1.565 & $<0.001$ & 1.524 & $<0.001$ & 1.514 & $<0.001$ \\
\hline \multicolumn{7}{|l|}{ Race } \\
\hline \multicolumn{7}{|l|}{ White (ref) } \\
\hline Other & 1.369 & 0.059 & 1.289 & 0.127 & 1.197 & 0.281 \\
\hline \multicolumn{7}{|l|}{ BMD T-score category } \\
\hline$\leq-2.5$ & 1.322 & 0.002 & 1.533 & $<0.001$ & 1.651 & $<0.001$ \\
\hline \multicolumn{7}{|l|}{$>-2.5$ (ref) } \\
\hline Unknown & 0.579 & $<0.001$ & 0.591 & $<0.001$ & 0.618 & $<0.001$ \\
\hline \multicolumn{7}{|l|}{ Smoking } \\
\hline \multicolumn{7}{|l|}{ Current smoker (ref) } \\
\hline Former smoker & 0.758 & $<0.001$ & 0.754 & $<0.001$ & 0.761 & $<0.001$ \\
\hline Never smoker & 0.715 & $<0.001$ & 0.715 & $<0.001$ & 0.711 & $<0.001$ \\
\hline Unknown & 0.336 & $<0.001$ & 0.345 & $<0.001$ & 0.356 & $<0.001$ \\
\hline \multicolumn{7}{|l|}{ Baseline BMI } \\
\hline \multicolumn{7}{|l|}{ Under/normal weight (ref) } \\
\hline Over weight & 0.805 & $<0.001$ & 0.779 & $<0.001$ & 0.739 & $<0.001$ \\
\hline Obese & 0.538 & $<0.001$ & 0.513 & $<0.001$ & 0.473 & $<0.001$ \\
\hline Very obese & 0.462 & $<0.001$ & 0.394 & $<0.001$ & 0.357 & $<0.001$ \\
\hline Missing & 0.726 & $<0.001$ & 0.710 & $<0.001$ & 0.701 & $<0.001$ \\
\hline Charlson Comorbidity Index & 0.955 & $<0.001$ & 0.963 & $<0.001$ & 0.968 & $<0.001$ \\
\hline Oral corticosteroid & 1.338 & $<0.001$ & 1.336 & $<0.001$ & 1.309 & $<0.001$ \\
\hline Rheumatoid arthritis & 1.395 & $<0.001$ & 1.512 & $<0.001$ & 1.732 & $<0.001$ \\
\hline
\end{tabular}

disadvantage of using data from a single healthcare system is that the prescribing patterns and, thus, predictors of treatment may not reflect prescribing patterns of other health systems or of US prescribers overall. Similarly, included patents reside in a single geographic region. Thus, caution must be made in generalizing these findings to other populations or the USA as a whole.

Second, while this study did not include fractures that were most likely due to trauma, it is still not possible from the data to ascertain if fractures were fragility related or primarily the result of an injury. Thus, fracture as a criterion for defining osteoporosis in this study may lack sensitivity and may help to explain why treatment rates were low in the fracture group.

Finally, there is debate about whether antiresorptive treatment should be initiated immediately after fracture [40, 41]. One recent study showed that zoledronate did not delay union of hip fracture [42]. However, another study examining patients with a humerus fracture showed that bisphosphonate use increased the risk of non-union between 3 and 12 months after the fracture [43]. This suggests that providers may wait for fragility fractures to heal before initiating bisphosphonate therapy. While most fractures would be healed in 90 days, the sensitivity analyses of 180 and 365 days for the treatment window indicate that the choice of a 90 day treatment window versus a longer window did not impact predictors of treatment or overall treatment rate.

\section{Conclusion}

In this study, we found that many patient characteristics that indicate fracture risk were predictive of oral bisphosphonate treatment in a cohort of females age 50 and older with at least one indicator for osteoporosis. Many of these associations have not been found in previous studies. However, several other known risk factors for fracture and osteoporosis were not found to be significant predictors of 
treatment, and the treatment rate for those with a prior fracture was low overall. This suggests that while prescribing patterns may be more consistent with recommendations than previously evidenced, there remains opportunity for improvement in the use of drug treatment to help avoid fractures in women with post-menopausal osteoporosis.

Conflicts of interest This study was supported by the Alliance for Better Bone Health (Procter \& Gamble Pharmaceuticals and SanofiAventis US Inc.).

\section{References}

1. Watts NB, Geusens P, Barton IP, Felsenberg D (2005) Relationship between changes in BMD and nonvertebral fracture incidence associated with risedronate: reduction in risk of nonvertebral fracture is not related to change in BMD. J Bone Miner Res 20(12):2097-2104

2. NOF Fast Facts. 2009; http://www.nof.org/osteoporosis/diseasefacts. htm. Accessed 3/17/2009

3. Braithwaite RS, Col NF, Wong JB (2003) Estimating hip fracture morbidity, mortality and costs. J Am Geriatr Soc 51 (3):364-370

4. Oleksik A, Lips P, Dawson A et al (2000) Health-related quality of life in postmenopausal women with low BMD with or without prevalent vertebral fractures. J Bone Miner Res 15(7):1384-1392

5. Ray NF, Chan JK, Thamer M, Melton LJ 3rd (1997) Medical expenditures for the treatment of osteoporotic fractures in the United States in 1995: report from the National Osteoporosis Foundation. J Bone Miner Res 12(1):24-35

6. McAdam-Marx C, Lafleur J, Kirkness C, Asche C (2007) Postmenopausal osteoporosis current and future treatment options. P\&T 32(7):392-402

7. Gehlbach SH, Fournier M, Bigelow C (2002) Recognition of osteoporosis by primary care physicians. Am J Public Health 92 (2):271-273

8. WHO (2003) Prevention and management of osteoporosis. Geneva

9. Brennan RM, Wactawski-Wende J, Crespo CJ, Dmochowski J (2004) Factors associated with treatment initiation after osteoporosis screening. Am J Epidemiol 160(5):475-483

10. Cole RP, Palushock S, Haboubi A (1999) Osteoporosis management: physicians' recommendations and womens' compliance following osteoporosis testing. Women Health 29(1):101-115

11. Cranney A, Tsang JF (2008) Leslie WD (2008) Factors predicting osteoporosis treatment initiation in a regionally based cohort. Osteoporos Int 20(9):1621-1625

12. Kirk JK, Spangler JG, Celestino FS (2000) Prevalence of osteoporosis risk factors and treatment among women aged 50 years and older. Pharmacotherapy 20(4):405-409

13. Marci CD, Anderson WB, Viechnicki MB, Greenspan SL (2000) Bone mineral densitometry substantially influences health-related behaviors of postmenopausal women. Calcif Tissue Int 66(2):113-118

14. Phillipov G, Mos E, Scinto S, Phillips PJ (1997) Initiation of hormone replacement therapy after diagnosis of osteoporosis by bone densitometry. Osteoporos Int 7(2):162-164

15. Riggs BL, Melton LJ 3rd (1995) The worldwide problem of osteoporosis: insights afforded by epidemiology. Bone 17(5 Suppl):505S-511S
16. Rubin SM, Cummings SR (1992) Results of bone densitometry affect women's decisions about taking measures to prevent fractures. Ann Intern Med 116(12 Pt 1):990-995

17. Siris ES, Miller PD, Barrett-Connor E et al (2001) Identification and fracture outcomes of undiagnosed low bone mineral density in postmenopausal women: results from the National Osteoporosis Risk Assessment. JAMA 286(22):2815-2822

18. Solomon DH, Brookhart MA, Gandhi TK et al (2004) Adherence with osteoporosis practice guidelines: a multilevel analysis of patient, physician, and practice setting characteristics. Am J Med 117(12):919-924

19. Torgerson DJ, Thomas RE, Campbell MK, Reid DM (1997) Randomized trial of osteoporosis screening. Use of hormone replacement therapy and quality-of-life results. Arch Intern Med 157(18):2121-2125

20. Yood RA, Harrold LR, Fish L et al (2001) Prevention of glucocorticoid-induced osteoporosis: experience in a managed care setting. Arch Intern Med 161(10):1322-1327

21. Ryder KM, Shorr RI, Tylavsky FA et al (2006) Correlates of use of antifracture therapy in older women with low bone mineral density. J Gen Intern Med 21(6):636-641

22. Freedman KB, Kaplan FS, Bilker WB, Strom BL, Lowe RA (2000) Treatment of osteoporosis: are physicians missing an opportunity? J Bone Joint Surg Am 82-A(8):1063-1070

23. Nayak S, Roberts MS, Greenspan SL (2009) Factors associated with diagnosis and treatment of osteoporosis in older adults. Osteoporos Int (In Press)

24. Epstein S (2006) Update of current therapeutic options for the treatment of postmenopausal osteoporosis. Clin Ther 28(2):151173

25. Nelson HD, Helfand M, Woolf SH, Allan JD (2002) Screening for postmenopausal osteoporosis: a review of the evidence for the U. S. Preventive Services Task Force. Ann Intern Med 137(6):529541

26. Deyo RA, Cherkin DC, Ciol MA (1992) Adapting a clinical comorbidity index for use with ICD-9-CM administrative databases. J Clin Epidemiol 45(6):613-619

27. Simonelli C, Chen YT, Morancey J, Lewis AF, Abbott TA (2003) Evaluation and management of osteoporosis following hospitalization for low-impact fracture. J Gen Intern Med 18 (1):17-22

28. Cuddihy MT, Gabriel SE, Crowson CS et al (2002) Osteoporosis intervention following distal forearm fractures: a missed opportunity? Arch Intern Med 162(4):421-426

29. Harrington JT, Broy SB, Derosa AM, Licata AA, Shewmon DA (2002) Hip fracture patients are not treated for osteoporosis: a call to action. Arthritis Rheum 47(6):651-654

30. Follin SL, Black JN, McDermott MT (2003) Lack of diagnosis and treatment of osteoporosis in men and women after hip fracture. Pharmacotherapy 23(2):190-198

31. National Osteoporosis Foundation (2008) Physician's guide to prevention and treatment of osteoporosis. National Osteoporosis Foundation, Washington

32. Kanis JA, McCloskey EV, Johansson H, Strom O, Borgstrom F, Oden A (2008) Case finding for the management of osteoporosis with FRAX-assessment and intervention thresholds for the UK. Osteoporos Int 19(10):1395-1408

33. Kanis JA on behalf of the World Health Organization Scientific Group (2008) Assessment of osteoporosis at the primary health care level. University of Sheffield, UK, WHO Collaborating Center

34. Delmas PD, Siris ES (2008) NICE recommendations for the prevention of osteoporotic fractures in postmenopausal women. Bone 42(1):16-18

35. Alendronate, etidronate, risedronate, raloxifene, strontium ranelate and teriparatide for the secondary prevention of osteoporotic 
fragility fractures in postmenopausal women: National Institute for Health and Clinical Excellence, 2007

36. Alendronate, etidronate, risedronate, raloxifene and strontium ranelate for the primary prevention of osteoporotic fragility fractures in postmenopausal women: National Institute for Health and Clinical Excellence, 2007

37. Curtis JR, Westfall AO, Allison JJ et al (2005) Longitudinal patterns in the prevention of osteoporosis in glucocorticoid-treated patients. Arthritis Rheum 52(8):2485-2494

38. Shah SK, Gecys GT (2006) Prednisone-induced osteoporosis: an overlooked and undertreated adverse effect. J Am Osteopath Assoc 106(11):653-657

39. Solomon DH, Katz JN, Jacobs JP, La Tourette AM, Coblyn J (2002) Management of glucocorticoid-induced osteoporosis in patients with rheumatoid arthritis: rates and predictors of care in an academic rheumatology practice. Arthritis Rheum 46 (12):3136-3142

40. Lin JT, Lane JM (2003) Bisphosphonates. J Am Acad Orthop Surg 11(1):1-4

41. Lauerman M, Issack $P$, Lane J. Bisphosphonates and Fracture Healing In Orthopaedic Fracture Patients. Canadian Orthopaedic Association Bulletin [February/March 2006; \#72:http:/www. coa-aco.org/coa_bulletin/issue_72.html. Accessed 19 March, 2009

42. Nordsletten L, Mesenbrink P, Magaziner J, et al. Association between timing of zoledronic acid infusion and hip fracture healing: HORIZON-RFT. American Academy of Orthopaedic Surgeons. Vol Las Vegas, NV2009

43. Solomon DH, Hochberg MC, Mogun H, Schneeweiss S (2009) The relation between bisphosphonate use and non-union of fractures of the humerus in older adults. Osteoporos Int 20(6):895-901 